20. Suter, P. M. Fairley, H. B., and Isenberg, M. D.: Optimum end-expiratory airway pressure in patients with acute pulmonary failure. N. Engl. J. Med., 292: 284 (1975).

21. Thomas, L. J., Griffo, Z. J., and Roos, A.: Effect of negative-pressure inflation of the lung on pulmonary vascular resistance. J. Appl. Physiol., 16: 45I (196I).

22. Whittenberger, J. L., McGregor, M., Berglund, E., and Borst, H. G.: Influence of state of inflation of the lung on pulmonary vascular resistance. J. Appl. Physiol., 15: 878 (1960).

23. The authors thank Ms. Valerie Cole and Ms. Nancy Miller for excellent technical assistance.
24. Some of these data were presented at the 1975 Southern Society for Pediatric Research meetings.

25. This research was supported by National Grants H1-16864-01 and HI-13749-05, and by cooperative funds of the Florida Heart Association and its chapters.

26. The current address of Dr. J. R. Hessler is: University of Tennessee Medical Center, Memphis, Tenn.

27. Requests for reprints should be addressed to: E. A. Egan, M.D., Department of Pediatrics, Box J-296, University of Florida College of Medicine, Gainesville, Fla. 32610 (USA).

28. Accepted for publication May 25, 1976.

\title{
Growth and Nutrition of Uremic Piglets
}

\author{
P. R. BETTS, ${ }^{(23)}$ M. D. MANN, AND J. WOLFSDORF \\ Department of Paediatrics and Child Health, University of Rhodesia, Salisbury, Rhodesia
}

\section{Extract}

Piglets aged 6 days were rendered uremic by subtotal nephrectomy and their growth and dietary intakes studied over the next 21 days. Eleven control piglets fed a voluntary intake of a sow's milk substitute (group $A$ ), 11 nephrectomized piglets fed a voluntary intake of the same feed ( $g r o u p B$ ), 6 nephrectomized piglets tube fed the same milk (group $C$ ), and 11 nephrectomized piglets fed a voluntary intake of a low protein, isocaloric food (group $D$ ) were studied. After nephrectomy the piglets had an initial rapid rise in blood urea concentration which had fallen by day 7 and then leveled out around $13 \mathrm{mmol} /$ liter in group $B$ and $8 \mathrm{mmol} /$ liter in group $D$.

After operation control piglets (group $A$ ) ate more from day 4 and were larger from day 7 than the nephrectomized piglets (group $B$ ). Those piglets tube fed (group $C$ ) were of a similar size to the controls but all died between day 7 and day 11 with associated high blood urea concentrations. Piglets fed the low protein, isocaloric feed (group $D$ ) were smaller than both the controls and group $B$. They also ate less food than the controls and those nephrectomized piglets in group $B$ which were on a voluntary intake of the normal feed.

\section{Speculation}

Reduced energy intake is related to growth retardation seen in children with chronic renal insufficiency. However, is this the cause or result of reduced growth velocity? Ensuring a satisfactory intake of energy and nutrients from birth may ensure an initial normal growth pattern in children with chronic renal insufficiency.

Short stature is a well recognized consequence of chronic renal insufficiency in childhood $(2,3,16)$. Reduced growth velocity occurs predominantly on presentation in infancy, and in later childhood when it is associated with the terminal stages of the disease (2). Most studies have concentrated on children in their terminal stage of disease and have shown that a reduced caloric intake is a major factor in this growth retardation $(3,16)$. In an animal model, Chantler et al. (4) have demonstrated both reduced growth and dietary intake in weaned rats after subtotal nephrectomy resulting in blood urea concentrations equivalent to severe renal failure.

Infants with renal insufficiency may have a rapid fall in weight centile over the first few months of life, with little evidence of subsequent catch-up growth (2). If this fall can be shown to be due primarily to calorie deficiency, then prevention at this stage may be possible by dietary means. The piglet may be a suitable animal model on which to study growth patterns in infancy. These animals have a rapid growth rate increasing from $1.5 \mathrm{Kg}$ at birth to $90 \mathrm{Kg}$ by 6 months of age when they are sexually mature. They can also be successfully fed from soon after birth on artificial milk, having first received colostrum. Furthermore, many aspects of renal physiology in the piglet are similar to those of the infant $(11,12)$.

The present study was undertaken in order to determine the growth and dietary intake of piglets rendered uremic in the first week of life and studied until age 1 month. The first part of the study compared the growth and voluntary intake of a sow's milk substitute of piglets rendered uremic by partial nephrectomy with values for healthy piglets. The second part of the study was an attempt to obtain normal growth by feeding nephrectomized piglets the same amount of milk as the controls had taken. In the third part of the study the growth of nephrectomized piglets was measured on a voluntary intake of an isocaloric, low protein feed, which is an analgous situation to some of the low protein feeds given in renal failure.

\section{METHODS}

Large White/Landrace cross piglets were taken from the sow at 6 days of age. Only male piglets were used because of the known difference in blood urea concentrations between the sexes (17). There were four groups: group $A$, controls (normal feed); group $B$, renals (normal feed); group $C$, renals (tube fed); and group $D$, renals (low protein feed). They were anesthetized with intraperitoneal sodium pentobarbitone $(20 \mathrm{mg} / \mathrm{kg})$ and the abdomen was opened by a left paramedian incision. Animals were made uremic 
by removing the right kidney and the upper and lower poles of the left kidney. Between half and two-thirds of the left kidney was removed, as a pilot study had shown that this results in a blood urea concentration of approximately $25 \mathrm{mmol} / \mathrm{liter}(150 \mathrm{mg} / 100$ $\mathrm{ml}) 48 \mathrm{hr}$ after operation. Hemostatis was obtained by digital pressure on the remaining kidney after covering the cut ends with an absorbable gelatin sponge (21). When animals were to be tube fed a gavage tube (Levin type, size $12 \mathrm{CH}$ ) was placed in the stomach, brought out through the cheek, and fixed in the midline between the scapulae. In the control animals the operation was limited to laparotomy and the exposure of both kidneys. Six animals who died in the first week following surgery were excluded from the study, as it appeared that the anesthetic and operation had contributed to their death. Throughout the study the day of operation was taken as day 0 .

All piglets received $20 \mathrm{ml} / \mathrm{kg}$ of half-strength Darrow's solution either intraperitoneally or subcutaneously at operation, and the same volume of normal saline subcutaneously the day after surgery to cover insensible losses. Intramuscular procaine penicillin and streptomycin were given at the time of operation and daily for the next 3 days.
The piglets were housed in separate cages for 3 weeks with an environmental temperature of $27^{\circ}$ and a normal diurnal light cycle. For the first $48 \mathrm{hr}$ after operation the animals were allowed only water. On day 2 a feed prepared from skimmed milk, maize, lard, egg, oil, and vitamin mix was introduced. The feed, which simulated sow's milk, supplied 104 cal, $6.8 \mathrm{~g}$ protein, $13.8 \mathrm{~g}$ carbohydrate, and $2.4 \mathrm{~g}$ fat/100 $\mathrm{ml}$. This was equivalent to $27 \%$ protein, $10 \%$ fat, and $55 \%$ carbohydrate by dry weight. The low protein milk feed supplied half the amount of protein and was made isocaloric with additional glucose. The fat content remained unchanged. Feed and water bowls for each piglet were weighed before they were placed in the cages and after they were removed. The difference between these weights was taken as the quantity of food (or water) consumed. Piglets on voluntary intake were fed three times a day. The amount of milk offered to these piglets was similar to the high scale of feeding described by Jones (9) and significant diarrhea did not occur. Tube-fed piglets were given the mean daily volume of feed taken by the control piglets of the same age. This was divided into equal aliquots and given six times a day as a gastric infusion. All the animals had free access to water.

Animals were weighed on a beam balance and blood was taken

Table 1. Weight and length of piglets studied ${ }^{1}$

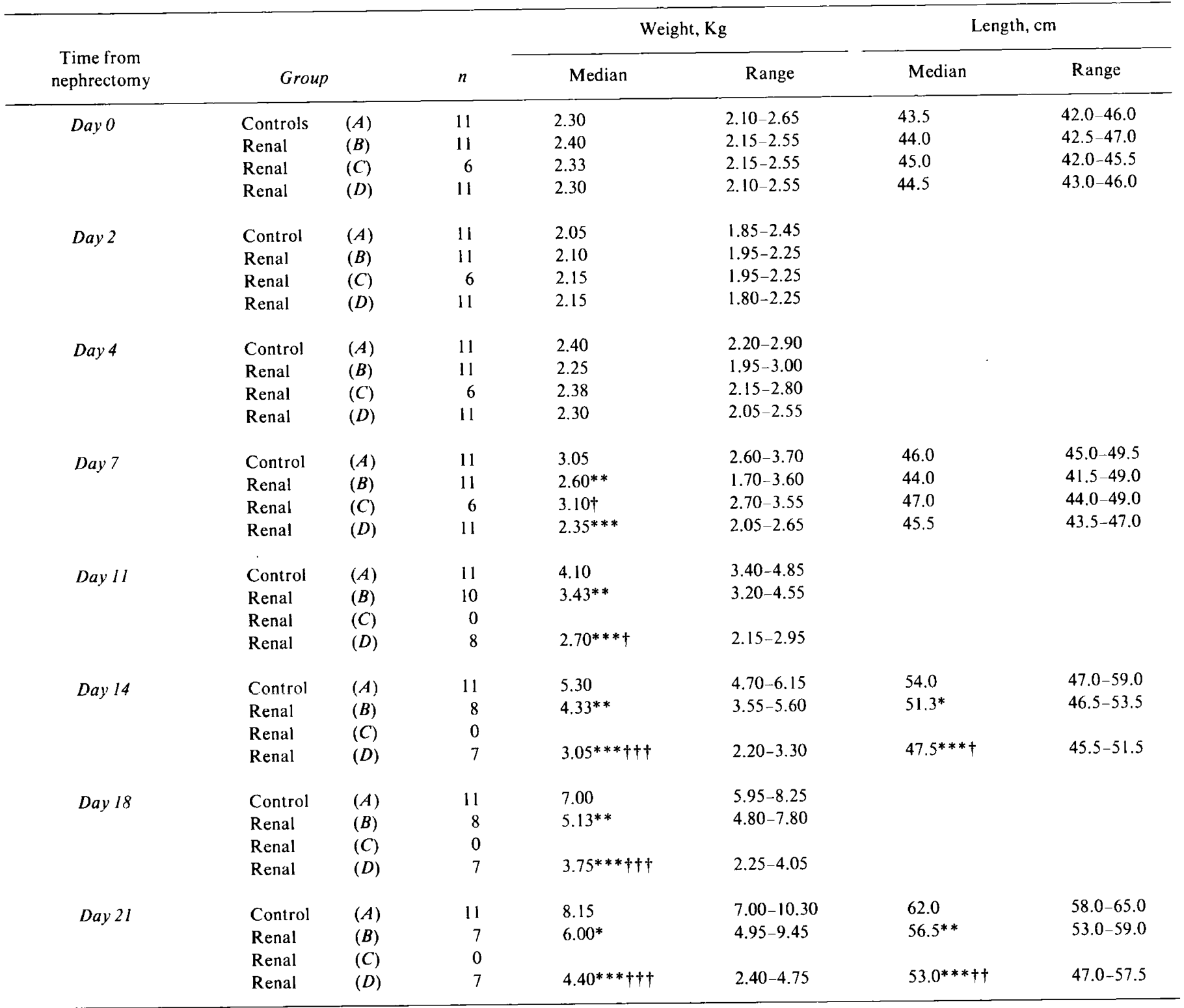

${ }^{1}$ Significantly different from group $A$ (control): ${ }^{*} P<0.05 ; * P<0.01 ; * * P<0.001$. Significantly different from $g r o u p B$ (renal): $+P<0.05 ; \dagger+1$ $<0.01 ;+\uparrow+P<0.001 . n$ : number of piglets alive. 
from a superior mediastinal vein on the day of operation (day 0 ), day 2 , and then twice weekly until day 21 . Length from the tip of the snout to the base of the tail was measured weekly.

Serum urea was measured by a phenol-hypochloride method after reaction with urease $(14,18)$. True serum creatinine was determined with an alkaline picrate reagent after absorption on to Fuller's Earth (19).

The Mann-Whitney U-test (15) was used to compare the groups in each part of the study. Results were taken as being significantly different when $P<0.05$.

\section{RESULTS}

The medians and ranges of the weights, lengths, caloric and water intakes, and the serum urea and creatinine concentrations are given in Tables 1-4. Eleven control animals (group $A$ ), 11 nephrectomized animals on a voluntary intake of sow's milk substitute (group $B$ ), 6 nephrectomized animals tube fed the sow's milk substitute (group $C$ ), and 11 nephrectomized animals on a voluntary intake of the low protein feed (group $D$ ) were included in the study. The numbers of piglets alive in the various groups during the study are given in Table 1.

\section{PART I}

The first part of the study was undertaken to compare the growth and voluntary food intake of control and nephrectomized animals when both groups received a milk similar in composition to sow's milk. During the 21-day study period, four nephrectomized animals died of uremia, one on day 7, two on day 12, and one on day 19.

All animals showed a rapid rise in blood urea concentrations after nephrectomy (Fig. 1) with a median of $29.0 \mathrm{mmol} /$ liter (174 $\mathrm{mg} / 100 \mathrm{ml}$ ) on day 4 (Table 2 ). After this there was a progressive fall in blood urea concentration, which leveled around $13 \mathrm{mmol} /$ liter $(80 \mathrm{mg} / 100 \mathrm{ml})$ from day 11 . Serum creatinine concentrations similarly rose and then fell (Fig. 2).

Control piglets (group $A$ ) weighed significantly more than the nephrectomized piglets (group $B$ ) from day 7 onwards (Fig. 3), and were longer from day 14 (Fig. 4). Between day 2 and day 4 the total daily food intakes of the two groups were similar (Fig. 5), although the blood urea concentrations of the piglets in group $B$ were highest during this period. From day 4 to day 21 the food intake of the controls was significantly greater than that of the nephrectomized animals. It is unlikely that this difference in food intake may be explained by differences in body mass, as the energy intakes per $\mathrm{kg}$ body weight of the two groups also differed significantly between day 4 and day 18.

Total water intake, which includes the water content in the milk feed, expressed both as absolute amount (Table 4) and per kg body weight was similar between the control and nephrectomized piglets (group B) over the 3-week study period, except for the period day 4 to day 6 . However, the nephrectomized piglets consumed less milk and their solute load was proportional to protein intake. When water intakes per $\mathrm{kg}$ body weight per $\mathrm{g}$ protein ingested were compared the nephrectomized piglets had drunk considerably in excess of the controls (Table 4).

\section{PART II}

As the first part of the study showed the piglet to be a suitable model for the study of chronic renal insufficiency in infancy, the second part was undertaken to compare the growth of control piglets with a group of six nephrectomized piglets (group $C$ ) tube fed the same quantity of food per day.

There was no difference between the weights of this group and the controls up to day 7 (Fig. 3) and weight gain in the tube-fed animals (group $C$ ) was significantly greater than that of the nephrectomized pigs on a voluntary food intake (group $B$ ) in the first part of the study. There was significant increase in length in these tube-fed piglets $(P<0.05$ using the paired Student's $t$-test $)$ during the 7-day period although no similar increase occurred in group $B$.

Water intake in these tube-fed piglets was increased up to $30 \%$ above that of the controls (Table 4). All six piglets in group $C$ then died between days 7 and 11 . They had frequent stools before death and rising blood urea concentrations which were greater than those in group $B$ on a voluntary food intake (Table 2). At postmortem examination they had gastric and small bowel dilation.

\section{PART III}

Nephrectomized piglets on a voluntary intake of sow's milk substitute ate less and were significantly smaller than the controls. All nephrectomized piglets tube fed the amount the controls had eaten died. The third part of the study compared the growth and voluntary food intake between the controls and a group of nephrectomized piglets fed a low protein isocaloric feed (group D).

Table 2. Blood urea and serum creatinine concentrations ${ }^{1}$

\begin{tabular}{|c|c|c|c|c|c|c|}
\hline \multirow{3}{*}{$\begin{array}{c}\begin{array}{c}\text { Time } \\
\text { from } \\
\text { nephyec- } \\
\text { tomy }\end{array} \\
\text { Day } 0\end{array}$} & & & \multicolumn{2}{|c|}{$\begin{array}{l}\text { Blood urea } \\
\text { concentration, } \\
\text { mmol/liter }\end{array}$} & \multicolumn{2}{|c|}{$\begin{array}{c}\text { Serum } \\
\text { creatinine } \\
\text { concentration, } \\
\mu \mathrm{mol} / \text { liter }\end{array}$} \\
\hline & \multicolumn{2}{|c|}{ Group } & Median & Range & Median & Range \\
\hline & Control & $(A)$ & 3.01 & $1.67-4.55$ & 72 & $12-102$ \\
\hline & Renal & $(B)$ & 3.17 & $1.17-6.68$ & 76 & $8-115$ \\
\hline & Renal & (C) & 4.00 & $2.42-5.85$ & 34 & $13-95$ \\
\hline & Renal & $(D)$ & 4.18 & $0.84-5.85$ & 57 & $27-69$ \\
\hline \multirow[t]{4}{*}{ Day 2} & Control & $(A)$ & 5.34 & $2.34-6.60$ & 60 & $24-115$ \\
\hline & Renal & $(B)$ & $20.88 * * *$ & $13.69-66.30$ & $279^{* * *}$ & $140-508$ \\
\hline & Renal & $(C)$ & $26.10^{* * *}$ & $18.20-40.10$ & $190 * * *$ & $163-284$ \\
\hline & Renal & (D) & $27.80 * * *$ & $13.30-51.90$ & $286^{* * *}$ & $183-354$ \\
\hline \multirow[t]{4}{*}{ Day 4} & Control & $(A)$ & 5.01 & $1.25-14.20$ & & \\
\hline & Renal & $(B)$ & $29.06^{* * *}$ & $10.35-107.90$ & & \\
\hline & Renal & (C) & $19.60 * * *$ & $12.90-28.70$ & & \\
\hline & Renal & $(D)$ & $22.40^{* * *}$ & $14.40-61.10$ & & \\
\hline \multirow[t]{4}{*}{ Day 7} & Control & $(A)$ & 4.34 & $3.01-7.60$ & 65 & $37-106$ \\
\hline & Renal & $(B)$ & $22.00 * * *$ & $7.68-108.10$ & $308^{* * *}$ & $110-369$ \\
\hline & Renal & (C) & $29.00 * * *$ & $18.70-66.60$ & $145^{* * *}$ & $95-235$ \\
\hline & Renal & $(D)$ & $16.45^{* * *}$ & $11.90-107.30$ & $163^{* * *}$ & $106-652$ \\
\hline \multirow[t]{4}{*}{ Day 11} & Control & $(A)$ & $4.72 *$ & $2.32-7.18$ & & \\
\hline & Renal & $(B)$ & $15.50 * * *$ & $8.90-77.90$ & & \\
\hline & Renal & (C) & & & & \\
\hline & Renal & $(D)$ & $17.20^{* * *}$ & $4.01-100.20$ & & \\
\hline \multirow[t]{4}{*}{ Day 14} & Control & $(A)$ & 5.34 & $2.21-7.85$ & 65 & $37-106$ \\
\hline & Renal & $(B)$ & $12.20 * * *$ & $9.69-26.70$ & $171^{* * *}$ & $125-398$ \\
\hline & Renal & (C) & & & & \\
\hline & Renal & $(D)$ & $8.30 * *$ & $3.40-39.10$ & $122 * \dagger \dagger$ & $54-229$ \\
\hline \multirow[t]{4}{*}{ Day 18} & Control & $(A)$ & 4.68 & $3.17-6.18$ & & \\
\hline & Renal & (B) & $13.50^{* * *}$ & $8.35-32.40$ & & \\
\hline & Renal & (C) & & & & \\
\hline & Renal & $(D)$ & $8.35 * *$ & $4.90-35.10$ & & \\
\hline \multirow[t]{4}{*}{ Day 21} & Control & $(A)$ & 5.18 & $2.25-6.35$ & 50 & $14-115$ \\
\hline & Renal & $(B)$ & $14.50^{* * *}$ & $10.70-40.90$ & $164 * * *$ & $150-309$ \\
\hline & Renal & (C) & & & & \\
\hline & Renal & $(D)$ & $7.34 * * \dagger$ & $5.20-12.80$ & $110^{*}+\dagger+$ & $54-160$ \\
\hline
\end{tabular}

${ }^{1}$ Significantly different from group $A$ (control): ${ }^{*} P<0.05 ;{ }^{*} P<$ $0.01 ;{ }^{* * *} P<0.001$. Significantly different from group $B$ (renal): $\dagger P<$ $0.05 ;+\uparrow<0.01 ;+\dagger+P<0.001$. 
Four piglets died during the 21-day study period, three from uremia and one from intestinal obstruction.

The nephrectomized piglets on a low protein feed in group $D$ were significantly smaller both in weight from day 7 and length from day 14 than both the controls and the nephrectomized piglets of group $B$ fed on the normal protein feed (Figs. 3 and 4). As in the first part of the study, food intake from day 2 to day 4 , over the period of highest blood urea concentration, was similar among all three groups. From day 4 onwards the food intake of the nephrectomized piglets on the low protein feed was significantly below that of the controls and from day 11 below that of group $B$ (Fig. 5). When food intake per $\mathrm{kg}$ body weight was compared, the nephrectomized piglets (group $D$ ) ate significantly less than the controls from day 4 to day 18 but there was no difference between the intake of the two renal groups (groups $B$ and $D$ ). These results were obtained despite the significant reduction in blood urea and creatinine concentrations in group $D$ compared with those nephrectomized piglets on the normal feed (group B).

Total water intake and water intake per $\mathrm{kg}$ body weight was significantly reduced in this nephrectomized group (group $D$ ) from day 4 onwards compared with the controls and those nephrectomized piglets in group $B$. This was because of group D's diminished milk intake, which contained water. However, when water intake was expressed per $g$ protein ingested, as a reflection of solute load, this was then increased approximately 3 times that of the controls (Table 4).

\section{DISCUSSION}

The pattern of blood urea and creatinine concentrations after subtotal nephrectomy in piglets is similar to that seen during the first few months of life in infants with renal insufficiency (2). In piglets after operation there is an initial rise in blood urea concentration which then falls, although remaining above that of the controls. This fall is probably due to hypertrophy $(10)$ and the resulting adaptation of the remaining kidney in response to the increased solute load. Children with chronic renal insufficiency from infancy, frequently due to congenital defects, commonly present soon after birth with raised blood urea concentrations and evidence of marked renal insufficiency. With correction of dietary intake, adequate water intake, and treatment of urinary tract infections, blood urea concentrations fall to asymptomatic levels and remain fairly constant for a number of years before the onset of terminal renal failure (2). The piglet has been shown to be a suitable model for the study of this pattern of renal insufficiency in infancy.

In the first few days of feeding, when the nephrectomized piglets had the highest blood urea and creatinine concentrations, they ate as much as the controls. It would appear that it is not these constituents per se that are responsible for the subsequent anorexia in these animals, and that whatever other factors associated with renal insufficiency may be implicated, they had not at this stage taken effect. This view is supported by the relative reduction in

Table 3. Energy intake of piglets studied ${ }^{1}$

\begin{tabular}{|c|c|c|c|c|c|c|}
\hline \multirow{3}{*}{$\frac{\text { Period }}{\text { Days } 0, I}$} & & & \multicolumn{2}{|c|}{ Calorie intake, Kcal/day } & \multicolumn{2}{|c|}{ Calorie intake, $\mathrm{Kcal} / \mathrm{Kg} /$ day } \\
\hline & \multicolumn{2}{|c|}{ Group } & Median & Range & Median & Range \\
\hline & Control & $(A)$ & & & & \\
\hline & Renal & $(B)$ & & & & \\
\hline & Renal & (C) & & & & \\
\hline & Renal & $(D)$ & & & & \\
\hline \multirow{4}{*}{ Days 2, 3} & Control & $(A)$ & 429 & $192-765$ & 207 & $89-328$ \\
\hline & Renal & (B) & 484 & $37-966$ & 233 & $18-368$ \\
\hline & Renal & (C) & 412 & & 192 & $183-211$ \\
\hline & Renal & $(D)$ & 558 & $263-644$ & 238 & $116-293$ \\
\hline \multirow[t]{4}{*}{ Days 4, 5, 6} & Control & $(A)$ & 889 & $495-1,105$ & 320 & $206-387$ \\
\hline & Renal & $(B)$ & $459^{* *}$ & $29-1,002$ & $188^{* * *}$ & $16-315$ \\
\hline & Renal & (C) & 889 & & 376 & $356-413$ \\
\hline & Renal & $(D)$ & $578^{* * *}$ & $405-778$ & $244^{* * *}$ & $169-346$ \\
\hline \multirow[t]{4}{*}{ Days $7,8,9,10$} & Control & $(A)$ & 1,162 & $614-1,558$ & 330 & $205-381$ \\
\hline & Renal & $(B)$ & $804^{* *}$ & $25-1,265$ & $288^{*}$ & $15-334$ \\
\hline & Renal & (C) & & & & \\
\hline & Renal & (D) & $624^{* * *}$ & $236-989$ & $263^{*}$ & $115-384$ \\
\hline \multirow[t]{4}{*}{ Days $11,12,13$} & Control & $(A)$ & 1,748 & $1,201-2,132$ & 371 & $297-404$ \\
\hline & Renal & $(B)$ & $1,147^{* *}$ & $970-1,725$ & $297 * *$ & $255-364$ \\
\hline & Renal & (C) & & & & \\
\hline & Renal & $(D)$ & $814^{* * *}$ & $374-998$ & $280^{* *}$ & $153-338$ \\
\hline \multirow[t]{4}{*}{ Days $14,15,16,17$} & Control & $(A)$ & 2,412 & $2,141-2,799$ & 386 & $366-445$ \\
\hline & Renal & (B) & $1,590^{* *}$ & $1,014-2,631$ & $338^{*}$ & $276-460$ \\
\hline & Renal & $(C)$ & & & & \\
\hline & Renal & (D) & $1,195^{* * *} \dagger$ & $389-1,366$ & $354^{* *}$ & $177-399$ \\
\hline \multirow[t]{4}{*}{ Days $18,19,20$} & Control & $(A)$ & 2,501 & $2,182-2,257$ & 338 & $310-362$ \\
\hline & Renal & $(B)$ & $2,140^{*}$ & $574-2,663$ & 316 & $118-398$ \\
\hline & Renal & (C) & & & & \\
\hline & Renal & $(D)$ & $1,385^{* * *}$ & $586-1,654$ & 328 & $252-398$ \\
\hline
\end{tabular}

${ }^{1}$ Significantly different from group $A$ (control): ${ }^{*} P<0.05 ;{ }^{* *} P<0.01 ;{ }^{* *} P<0.001$. Significantly different from group $B$ (renal): $+P<0.05$; $\dagger+P<0.01 ;+\dagger+P<0.001$. 
UREMIC PIGLETS: GROWTH AND NUTRITION

Table 4. Water intake of piglets studied ${ }^{1}$

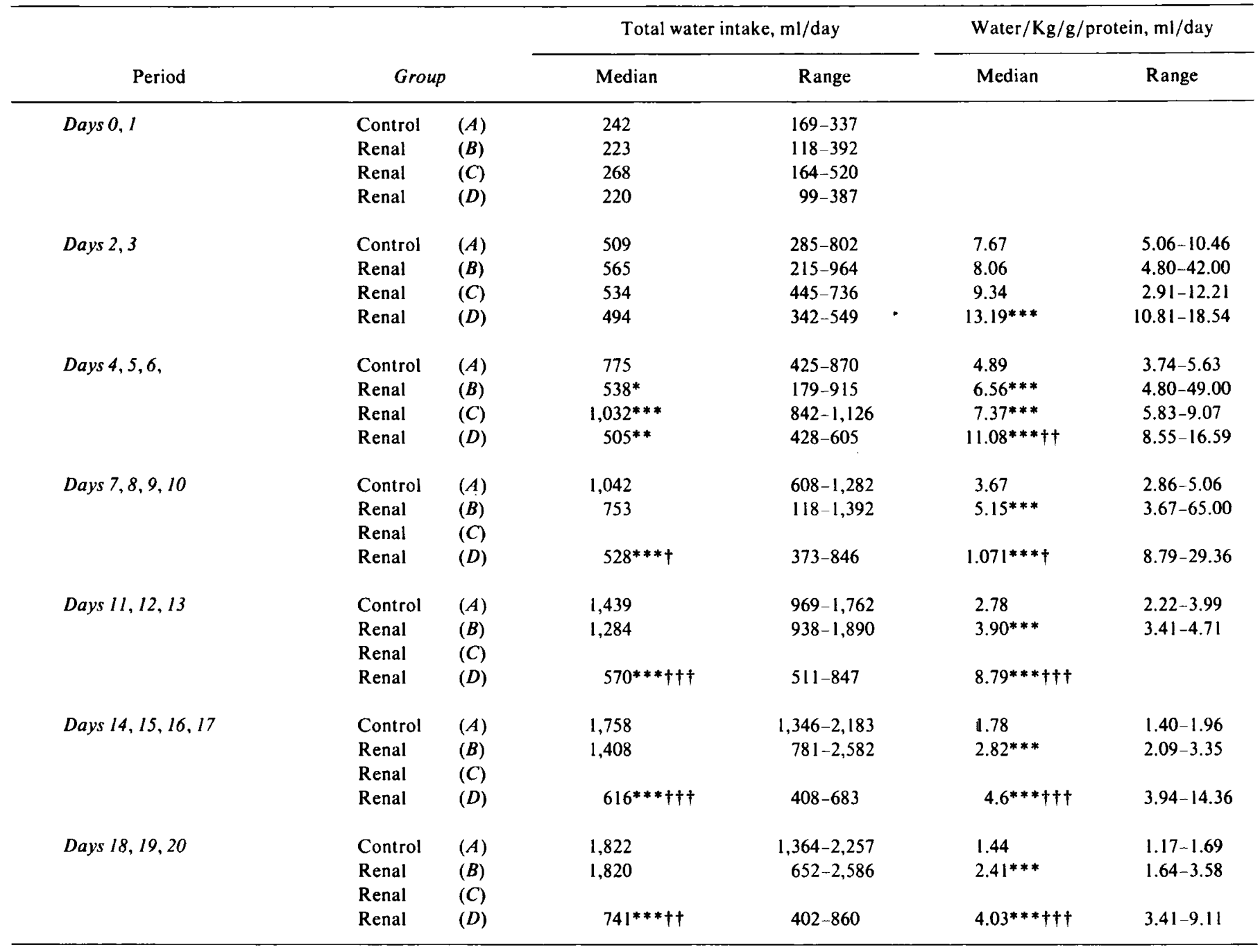

${ }^{1}$ Significantly different from group $A$ (control): ${ }^{*} P<0.05 ;{ }^{* *} P<0.01$; ${ }^{* * *} P<0.001$. Significantly different from group $B$ (renal): $+P<0.05$; t† $P<0.01$; + t+ $P<0.001$.

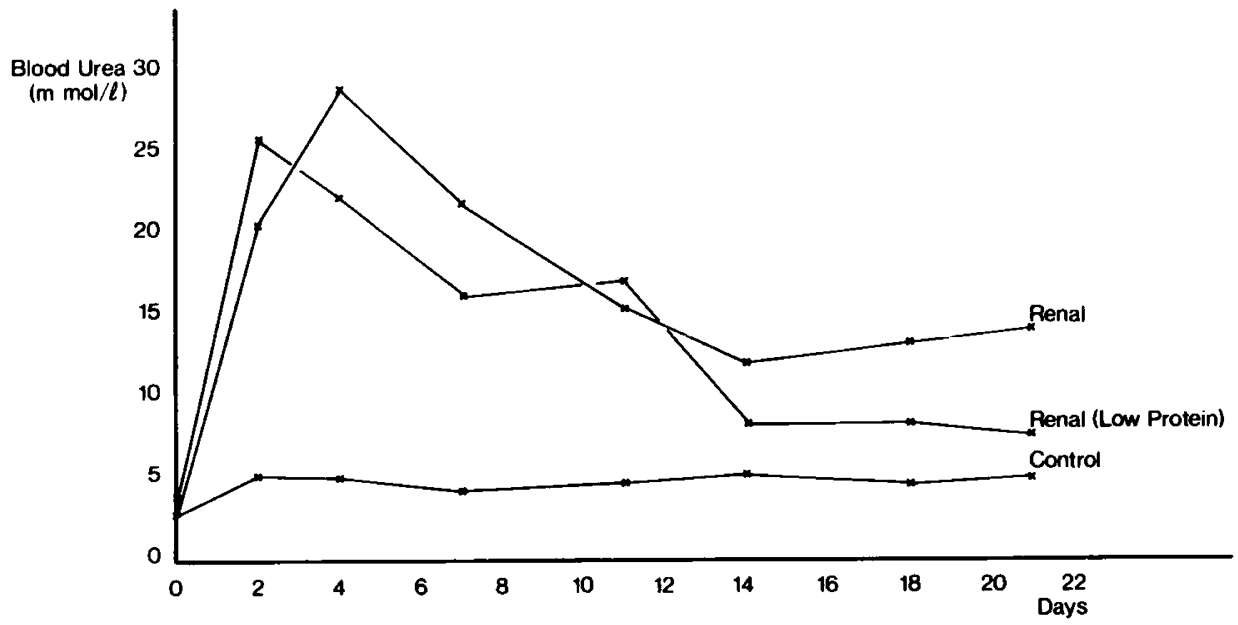

Fig. 1. Median blood urea concentrations in group $A$ (control), group $B$ (renal), and group $D$ (renal, low protein) piglets after nephrectomy. Statistical differences are given in Table 2.

food intake found after day 4 , when blood urea levels were falling. There was also no increase in food intake when the blood urea concentration fell to levels regarded as being asymptomatic (5). Blood urea and creatinine concentrations in the three nephrectomized groups were similar on day 2 after operation, suggesting they had the same degree of renal insufficiency. The lower creatinine concentrations subsequently found in group $D$ were therefore probably due to reduced growth and muscle mass.

Evidence of growth retardation occurred at milder degrees of renal insufficiency than previously reported in the study on rats by 
Chantler et al. (4) and persisted when blood urea concentrations were at "asymptomatic" levels, with no evidence of catch-up growth to compensate for the period of reduced growth velocity. Widdowson and McCance (20) have emphasized that there is a critical point in development when the size of an animal, arising from its previous plane of nutrition, determines its appetite thereafter, and hence its rate of growth and dimensions of maturity. A small size at this critical time brought about by undernutrition is not followed by catch-up growth, however liberal the diet. In children and piglets with renal insufficiency infancy may be a comparable critical period. Further studies are required to determine whether catch-up growth would occur later in piglets, but in children who have been malnourished in infancy for other reasons catch-up growth may not occur until puberty (7) and this is the very time that many children with renal insufficiency reach the terminal stages of their disease (2).

It has been suggested that excess water intake in chronic renal insufficiency may suppress appetite, leading to a decreased caloric intake (3). The results show that the uremic piglets, although eating less food, had very little more total fluid intake than the controls and this was therefore unlikely to be responsible for anorexia. However, water intake, per $\mathrm{g}$ protein ingested, was considerably increased in these piglets, and had their food intake been similar to that of the controls, then water intake would by necessity have been increased to deal with the increased solute load. This was clearly demonstrated in the tube-fed group who had a water intake up to $30 \%$ greater than the controls.

Piglets in group $D$ given a low protein, isocaloric food for 3 weeks ate significantly less than those nephrectomized piglets fed normal food and were proportionately smaller throughout the whole of the study period. This low protein feed, although isocaloric, had a protein content below the requirements of piglets at this age (1). There was no evidence that the uremic piglets in group $D$ ate more food to compensate for this. Thus, a decrease in protein content of feeds to below the required minimum intake had even further detrimental effect upon growth despite the decrease in blood urea and creatinine concentrations in those piglets. Further evidence that poor growth was primarily due to the reduced protein

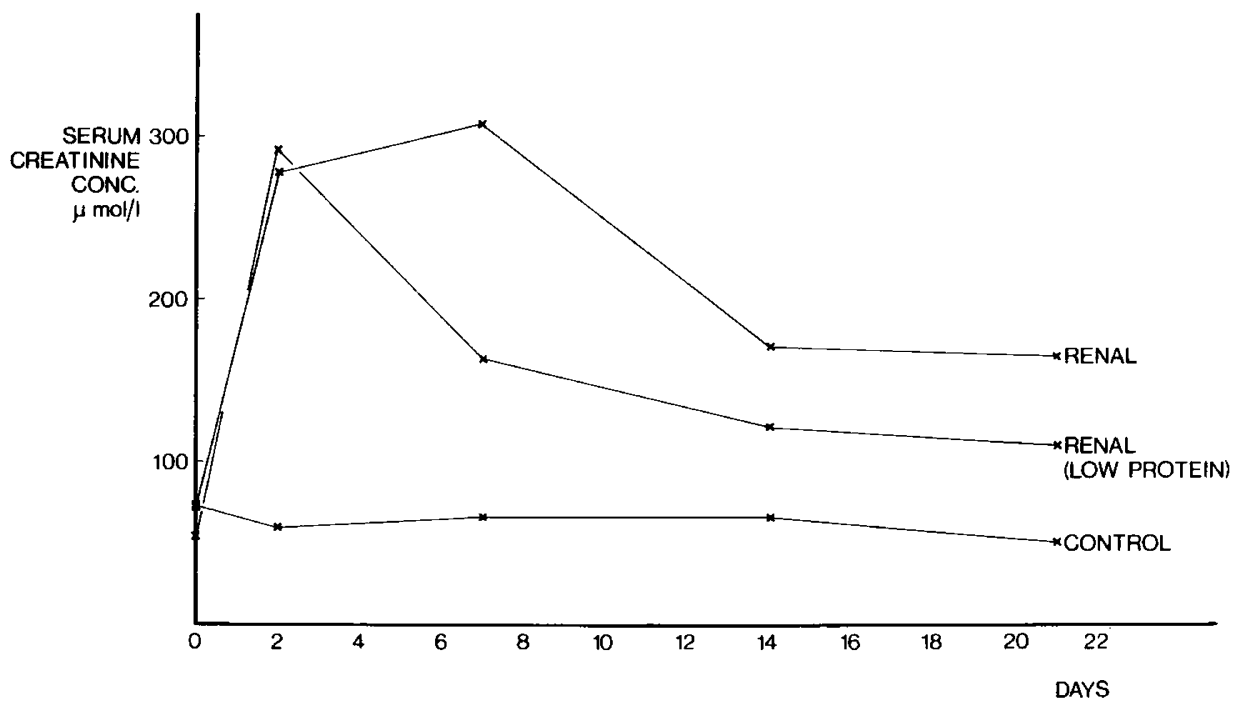

Fig. 2. Median serum creatinine concentrations in group $A$ (control), group $B$ (renal), and group $D$ (renal, low protein) piglets after nephrectomy. Statistical differences are given in Table 2.

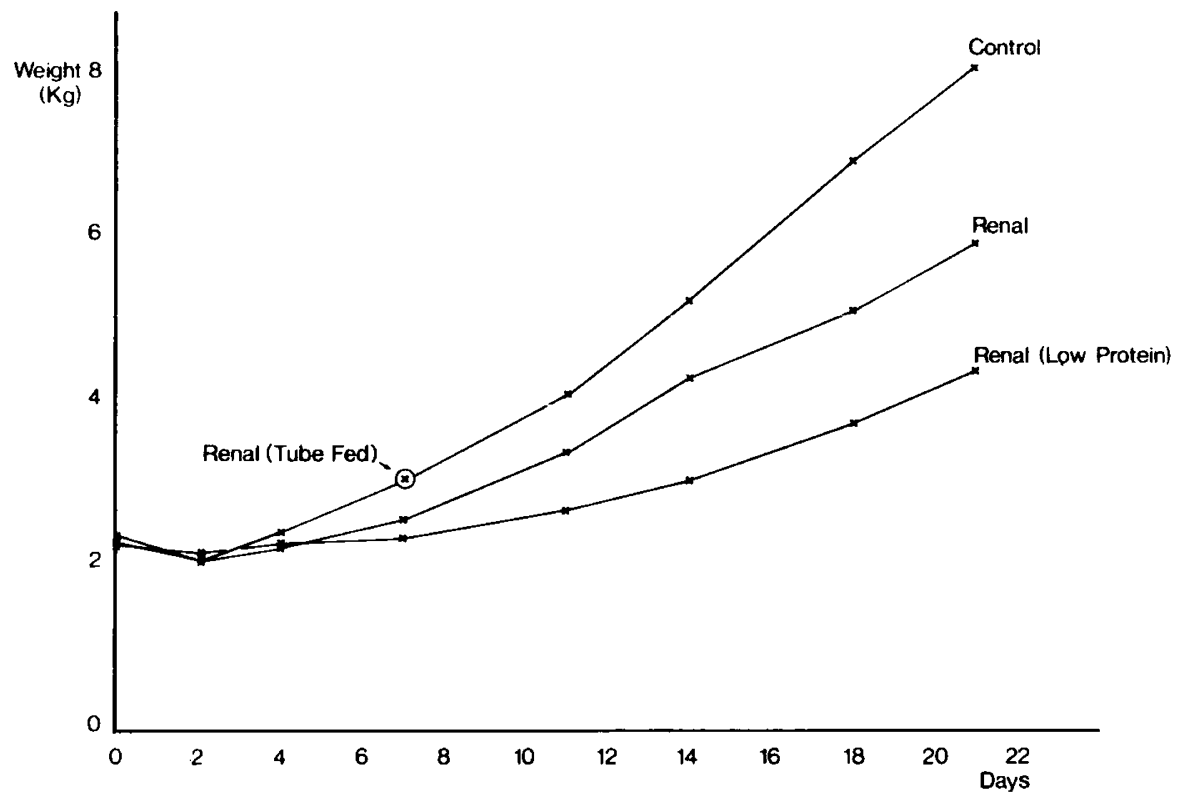

Fig. 3. Median body weights of group $A$ (Control), group B (renal), group $C$ (renal, tube fed), and group $D$ (renal, low protein) piglets after nephrectomy. Statistical differences are given in Table 1. 


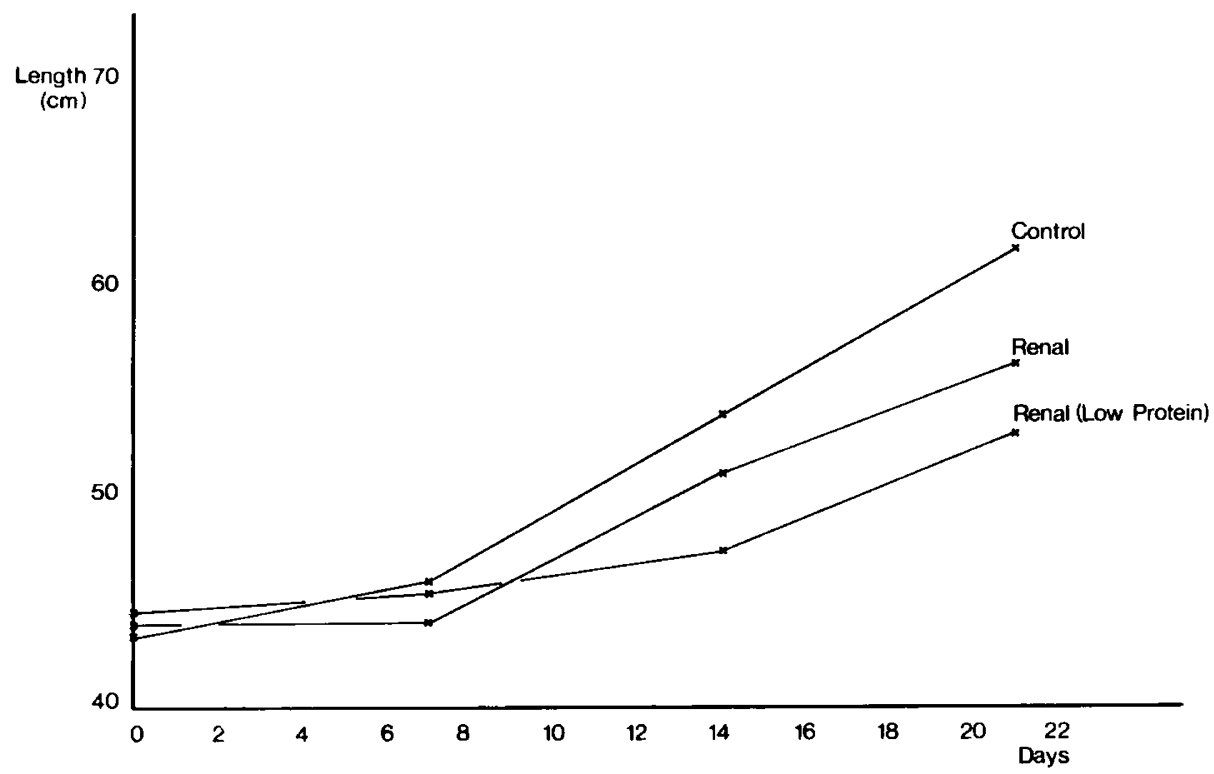

Fig. 4. Median length of group $A$ (control), group B (renal), group $D$ (renal, low protein) piglets after nephrectomy. Statistical differences are given in Table 1 .

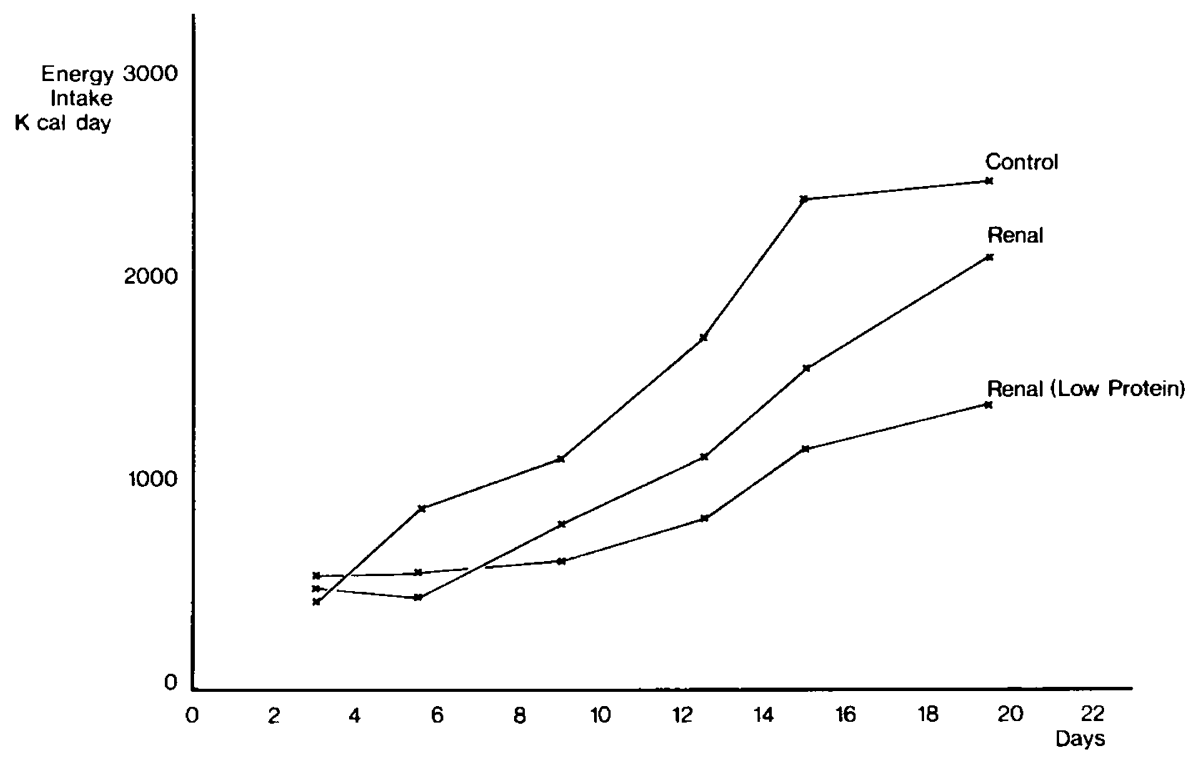

Fig. 5. Median energy intakes of group $A$ (control), group B (renal), group $D$ (renal, low protein) piglets after nephrectomy. Statistical differences are given in Table 3.

intake is given by Filer and Churella (8), who fed normal piglets similar low protein feeds and demonstrated reduced growth. Unfortunately, they did not estimate the quantity of food eaten by the piglets.

In an attempt to assess whether normal growth was possible in uremic piglets, group $C$ was tube fed an equivalent daily amount of the same feed as the controls. There was no difference in the weight gain between the controls and the tube-fed group during the first week after operation and the tube-fed group was heavier than those nephrectomized piglets on a voluntary intake. A significant increase in length also occurred in the tube-fed piglets over the 7-day study period whereas no such increase occurred in those nephrectomized piglets on a voluntary intake of normal feed. This suggests that weight increases were not due to salt or water retention and the growth of those nephrectomized tube-fed piglets (group $C$ ) was significantly greater than that of the piglets in group $B$ on a voluntary food intake. Although growth was satisfactory the tube-fed group died after 1 week from the effects of uremia with dilated small bowel and evidence of food intolerance. It was uncertain whether this dilation was a consequence of the uremia or the tube feeding. It would appear that these piglets would not tolerate the increased food intake necessary to sustain normal growth.

Chantler et al. (4) suggested that calories may be less efficiently utilized for growth in the uremic animal. In the present study weight gain was identical in the control and nephrectomized animals fed the same amounts. These findings agree with those of MacDonell and Holliday (13) and Diaz et al. (6) who pair-fed control and uremic rats and showed that their growth was similar. There is therefore no evidence from these various studies of an increased caloric cost of growth in renal failure.

It appears that a reduction in energy intake is of prime importance in the growth retardation seen in even mild renal insufficiency, but is this the cause or result of reduced growth? Normal growth was achieved for a short period by tube feeding uremic piglets, although this resulted in their death. Thus, as a compensatory measure, it is possible that the body may aim to reduce growth in parallel with the degree of remaining functioning 
renal tissue. A reduced dietary intake would then follow as a secondary effect. Nine-tenths of the protein nitrogen in the food of a newborn piglet is incorporated into its tissue and never presents itself to the kidney for excretion as urea (12). Thus, if growth velocity is reduced, energy and protein requirements should be correspondingly reduced, or an increased load would be presented to the kidney for excretion. If these results can be extrapolated to infants with chronic renal insufficiency, a compromise should be reached when advising feeds. Protein intake may be reduced but not below the minimum recommended for normal children, and the maximal voluntary intake should be offered. Forced feeding, resulting in too high a blood urea concentration, should be avoided. Because of the high solute load per unit of functioning kidney these infants may also require a total water intake, per $g$ protein ingested, up to $30 \%$ greater than normal.

\section{SUMMARY}

Newborn piglets rendered uremic by subtotal nephrectomy were taken as an animal model to study the dietary intake and growth of infants with chronic renal insufficiency. At blood urea concentrations around $15 \mathrm{mmol} /$ liter the piglets had a reduced voluntary intake of a sow's milk substitute and diminished growth when compared with a control group. Tube feeding nephrectomized piglets volumes of feed equal to those consumed by controls resulted in initial satisfactory growth but the piglets then all died with high blood urea concentrations. Nephrectomized piglets offered a voluntary intake of a low protein, isocaloric feed ate even less than the nephrectomized animals on the sow's milk substitute and were smaller despite lower blood urea and creatinine concentrations.

These results indicate that a decreased food intake is a major factor in the growth retardation seen in chronic renal insufficiency. Furthermore, the protein content of feeds should not be reduced below the minimum recommended, and maximal voluntary intakes of feed should be offered.

\section{REFERENCES AND NOTES}

1. Agricultural Research Council: The Nutrient Requirement of Farm Livestock. No. 3, Pigs (1966).
2. Betts, P. R., and Magrath, G.: Growth pattern and dietary intake of children with chronic renal insufficiency. Brit. Med. J., I: 189 (1974).

3. Chantler, C., and Holliday, M. A.: Growth in children with renal disease with particular reference to the effects of calorie malnutrition. Clin. Nephrol., I: 230 (1973).

4. Chantler, C., Lieberman, E., and Holliday, M. A.: A rat model for the study of growth failure in uraemia. Pediat. Res., 8: 109 (1974).

5. de Wardner, H.: The Kidney, p. 137 (J. \& A. Churchill Ltd. London, 1958)

6. Diaz, M., Kleinknecht, C., and Broyer, M.: Growth in experimental renal failure: Role of calorie and amino acid intake. Kidney Int. 8: 349 (1975).

7. Dreizen, S., Spirakis, C. N., and Stone, R. E.: A comparison of skeletal growth and maturation in undernourished and well nourished girls before and after menarche. J. Pediat., 70: 256 (1967).

8. Filer, L. J., and Churella, H.: Relationship of body composition, chemical maturation, homeostasis and diet in the newborn mammal. Ann. N.Y. Acad. Sci., 110: 380 (1963).

9. Jones, A. S.: Problems of nutrition and management of early weaned piglets. Proc. Brit. Soc. Anim. Prod., p. 19 (1972).

10. Kaufman, J. N., Hardy, R., and Hayslett, J. P.: Age dependent characteristics of compensatory renal growth. Kidney Int., 8: 59 (1975).

11. McCance, R. A., and Widdowson, E. M.: Metabolism, growth and renal function of piglets. J. Physiol., 133: 373 (1956).

12. McCance, R. A., and Widdowson, E. M.: Physiology of the newborn animal. Lancet, ii: 585 (1957).

13. MacDonell, R. C., and Holliday, M. A.: Appetite and nutrition in uraemic rats. Abstr. Amer. Soc. Nephrol., p. 71 (1973).

14. Munro, H. N., and Fleck, A.: In: H. N. Munro: Mammalian Protein Metabolism, Vol. III, Chapt. 30, pp. 431-438, 49I (Academic Press, New York, 1969).

15. Siegel, S.: Nonparametric Statistics for the Behavioural Sciences (McGraw-Hill Book Co., New York, 1956).

16. Simmons, J. M., Wilson, C. J., Potter, D. E., and Holliday, M. A.: Relation of calorie deficiency to growth failure in children on haemodialysis and the growth response to calorie supplementation. N. Engl. J. Med., 285: 653 (1971).

17. Tumbleson, M. E., Middleton, C. C., Thurley, O. W., and Hutchinson, D. P.: Serum biochemic and hematologic parameters of Hormel minature swine from 4 months to 9 months of age. Lab. Anim. Care, 19: 345 (1969).

18. Varley, H.: Practical Clinical Biochemistry, Ed. 3, p. 112 (William Heinemann, London, 1966).

19. Varley, H.: Practical Clinical Biochemistry, Ed. 4, p. 197 (William Heinemann, London, 1967).

20. Widdowson, E. M., and McCance, R. A.: New thoughts on growth. Pediat. Res., 9: 154 (1975).

21. Sterispon, Allen and Hanburys Ltd., London.

22. The authors acknowledge the Secretary of Health in Rhodesia for permission to publish.

23. Requests for reprints should be addressed to: P. R. Betts, M.D., University of Birmingham, Institute of Child Health, Francis Rd., Birmingham B16 8ET (England).

24. Accepted for publication May 24, 1976 